\title{
The Rhoton Collection
}

\author{
Jeffrey Sorenson ${ }^{1,2}$ \\ ${ }^{1}$ Department of Neurosurgery, University of Tennessee, Tennessee, \\ United States \\ 2 Semmes-Murphey Clinic, Memphis, Tennessee, United States
}

J Neurol Surg B 2016;77:294-296.
Address for correspondence Jeffery Sorenson, MD, Department of Neurosurgery, University of Tennessee Health Science Center, College of Medicine, 1211 Union Avenue Suite 200 Memphis, TN 38104, United States (e-mail: jsorenson@semmes-murphey.com).
Life is short, art is long. Dr. Rhoton understood the value of art and craft in his work, continuously elevating them to new heights in his laboratory, even as his physical form began to fail. Art had taken its rightful place in the study of anatomy during the Renaissance with the publication of Vesalius' De humani corporis fabrica. This was a major departure from the unillustrated books of Galen and other ancient anatomists, which had asked readers to perform the impossible task of visualizing human anatomy from a written description. Since Vesalius, artistic technique has been the most potent tool for making anatomy more comprehensible, so it was not surprising to find that Dr. Rhoton's modest suite of rooms at the Brain Institute was as much an art studio as a laboratory. Dr. Rhoton was very proud of the artistic results his fellows were achieving there. He repeatedly referred to them as modern day Michelangelos, which is not so far-fetched, as their dissections are essentially sculptures created by precise subtraction of material until a masterpiece remains. Just as Lorenzo de' Medici took in the young Michelangelo for training in the finest techniques of sculpture, Dr. Rhoton brought young, bright, motivated people from all over the world to learn the art and craft of anatomical dissection before making world-class contributions of their own. We also know that Michelangelo's deep interest in human anatomy and the brain led him to perform dissections and contemplate illustrating an anatomy textbook. I am certain that if Dr. Rhoton's laboratory had existed in Renaissance Florence, Michelangelo would have done a fellowship and we would still be admiring the results centuries later.

I remember seeing my first three-dimensional (3D) lecture from Dr. Rhoton at a skull base course in Memphis in 2002. It was immediately clear to me that, other than performing your own dissections, this was the best way to learn neuroanatomy. Complex relationships were revealed in a way that I'd never seen before in a textbook or in surgery. Not only that, but the visual beauty was stunning, producing the same euphoric feeling I had when I first visited Michelangelo's Sistine Chapel. I wanted to somehow pause his lectures so that I could study each image for an hour, but the slides kept advancing and were soon back in their boxes and on the way to the next city. I would have to wait another year to see it again. Nearly a decade later, at the same course, I learned about an American Association of Neurological Surgeons' initiative led by Drs. Jon Robertson and William Couldwell to fund the curation of Dr. Rhoton's work. Dr. Rhoton agreed to meet us in Gainesville to review a proposal. Fortuitously, 3D televisions were just hitting the market and we were able to render a few minutes of his cavernous sinus lecture as a 3D movie by the time of our first trip to the Brain Institute in October 2010. As Dr. Rhoton watched the lecture on a 3D television for the first time, he was astonished by how the images were much more vivid than he had ever seen them before. He agreed to move forward with the project and work began in earnest.

Early on, we appreciated that this effort was going to be like curating a great collection of art, so the name 'Rhoton Collection' was coined. Dr. Rhoton could have easily decided to monetize his collection by charging a subscription fee, but he had a singular goal for his body of work: making neurosurgery more accurate, gentle, and safe through better knowledge of anatomy. The whole world had selflessly come to Gainesville to help him create the collection, so in return he wanted to share it with as many people throughout the world as possible. With this goal in mind, the challenge for us was to maximize the educational impact of his work by inserting it into every conceivable situation in which it could improve understanding. This meant moving beyond the limitations of textbooks and leveraging database technologies that could instantaneously search and reorganize the material as needed. The whole collection should be at the surgeon's fingertips at all times, which was becoming possible with smart phones. It should be interactive and hyperlinked for exploratory study, but also in video form for passive learning. Finally, it should support projectors and large screens, both in two-dimension (2D) and 3D, so that lecturers around the world could quickly conjure some of the magic of Dr. Rhoton's 3D presentations. Fortunately, web browser technology was just beginning to reach the level of sophistication needed to deliver this wish list of features. (c) 2016 Georg Thieme Verlag KG Stuttgart · New York
DOI http://dx.doi.org/ $10.1055 / \mathrm{s}-0036-1584944$. ISSN 2193-6331. 


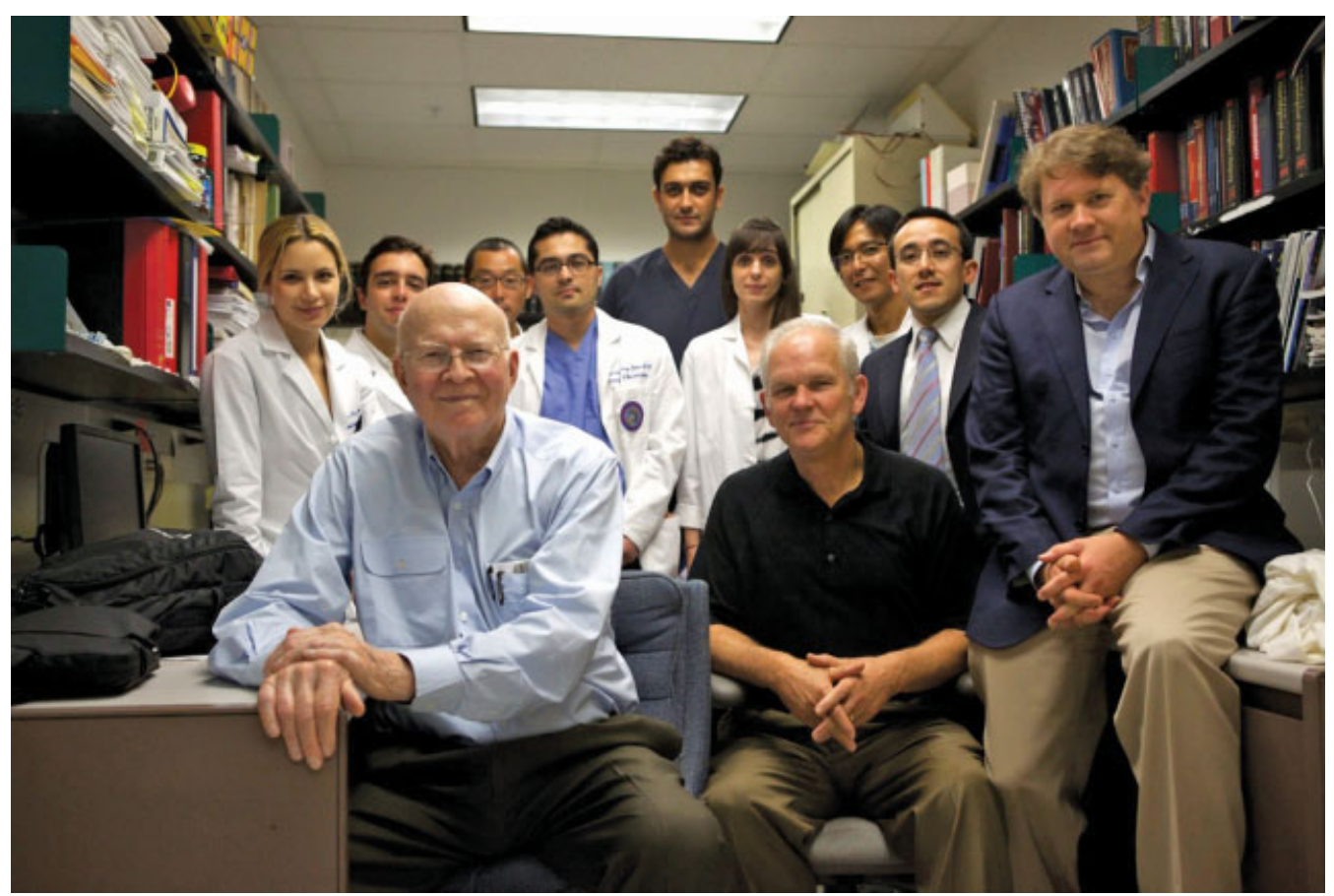

Fig. 1 Drs. Rhoton, Robertson, and Sorenson (front row) surrounded by the many wonderful fellows working in the lab during one of the visits to Gainseville.

Since the study of anatomy is inherently visual, another goal was to keep the images at the center of the reader's attention as much as possible. Therefore, the slide show paradigm was adopted, which made the anatomy topics easily adaptable to both podium presentations and small smartphone screens. It is also a natural format for surgical cases, which are integrated with the anatomy topics. Each slide contains images or video clips, and a caption with keywords that trigger structure highlights. These captions are useful for self-paced, interactive study. A full screen mode displays the slides as a presentation, without the captions, for use in teaching conferences. As the speaker advances the presentation, the next structure of interest is highlighted or the next slide is shown. The Web site formats the slide show on the fly for all devices, ranging from smartphones to projectors. The use of hyperlinking within the slide shows allows related cases or topics to be quickly explored.

After deciding upon the goals and architecture of the project, the first priority was to capture his standard lectures and produce 3D movies from them. The lectures were recorded live during courses with a video camera, but his voice was the only part of the recording that would be used in the final production. High resolution images used for the lecture were imported into the Web site and arranged as a slide show with his narrative transcribed into each slide caption. Aligned images suitable for 3D television were generated in the Web site, and then downloaded into video-editing software to be combined with Dr. Rhoton's audio track. The most challenging part of the production was labeling the 3D images. We decided to create a 3D drawing tool for the Web site, which allowed anatomical structures within the images to be highlighted interactively. The drawings could also be downloaded and imported into video-editing software to highlight structures in the video lectures. Dr. Rhoton liked this method of highlighting very much, so residents and medical students were then recruited to help transcribe the lectures and make thousands of drawings. Although this was more tedious than conventional labeling, it allowed each structure to be more precisely defined while preserving the beauty of the images better than an overlay of lines or arrows. Considering the extensive time and effort required to create these images in the laboratory, the time investment required to make the drawings was appropriate. Students and residents were motivated by the idea that their drawings would become part of the fabric of the collection, increasing the educational value of the images for the life of the collection. They were also learning a lot about anatomy.

Our meetings with Dr. Rhoton in Gainesville fell into a routine from the very beginning. Dr. Rhoton would meet Drs. Robertson, Couldwell, and I at the University Hilton restaurant for breakfast, where we would catch up. He would then drive us to the Brain Institute at the University of Florida, along the way pointing out all of the new buildings going up on campus. In the conference room, his fellows would have already set up the 3D television. Dr. Rhoton, his fellows, and our team would don our 3D glasses and begin scrutinizing a video. I would have stayed up late the night before at the hotel, making last minute changes and hoping that the quality of our work would measure up to the standards of Dr. Rhoton's laboratory. There was plenty of free coffee to mitigate sleep deprivation. After taking notes on the lectures, we would then review progress on the Web site and discuss everyone's ideas for further developments. We would break midafternoon and meet Dr. Rhoton for dinner, where he would share stories about his life, laboratory, travels, and fellows. He was always 
effusive about the success of his fellows, which had repeatedly validated the value of time spent in the laboratory. He reminded us that above and beyond the educational output of the laboratory, neurosurgery throughout the world benefitted from the expertise of his fellows. During our visits we came to appreciate the deep anatomical knowledge of his fellows, who would sometimes make important corrections that everyone else in the room had missed, including Dr. Rhoton.

Since the spring of 2011, nine 3D video lectures by Dr. Rhoton have been released. The initial lectures were released on a 3D Blu-ray disc and were the first neurosurgical anatomy movies in this format. All of the lectures are also available on YouTube. Six additional lectures will be released this year-three narrated by Dr. Rhoton and three by his fellows. We expect additional lectures in the future from several of his fellows. In addition, short videos are being produced for every anatomical structure. To manage this large number of anatomy videos, the Web site has been modified to edit and render them in the cloud so that videoediting software will no longer be necessary. His collection of slides has now been scanned, which required multiple high resolution scanners running under the supervision of a full-time employee for over 2 years. Additional images obtained after the laboratory transitioned to digital photography are also being added to the collection. These will total over 100,000 images. The process of preparing the images for upload into the database involves 3D alignment, and corrections of exposure and color. After they are uploaded, the images are tagged with keywords so that they can be searched by anatomical structure, perspective, and approach. The Web site generates multiple 2D and 3D versions of the images and applies the Rhoton Collection watermark.

By design, the Rhoton Collection challenges us to build upon Dr. Rhoton's work. On the Web site, his images can be regarded as a large set of building blocks, which can be assembled into ad hoc topics or added to cases. To maximize the educational impact of the anatomy images and topics, they must be integrated with surgical cases, so we have begun an effort to collect a large number of cases that will be crossreferenced to topics in the Rhoton Collection. These cases may also become collections in their own right. In fact, it was Dr. Rhoton's hope that his generous gift would inspire others to donate their teaching files, whether they are images or surgical videos. Several prominent neurosurgeons are now doing so. The value of each existing collection only increases as others are added and cross-referenced.

Of course, it was never the intention for all of the material to be locked into the Rhoton Collection Web site. The images are freely downloadable from the Web site for use in presentations or publications as long as the Rhoton Collection is credited. Even more interesting is the possibility of using the collection as a digital reference embedded within other online resources. The first example of this is the Journal of Neurosurgery, which is working on integrating the Rhoton Digital Reference into online journal articles so that anatomical structures can be quickly reviewed in popup windows without having to leave the article.

It has been a tremendous honor for us to have had the opportunity to work with Dr. Rhoton, and to become friends with him and several of his fellows. I have learned much about work and life from him. The plans we developed with Dr. Rhoton will keep us busy for years. Future work will include finishing the basic topics and videos for all anatomical structures, additional lectures from his fellows, correlating his anatomical images to radiological images, adding more surgical cases, and translating the lectures and topics into multiple languages. Starting this summer, monthly topics will be released, gently reminding the neurosurgical and skull base community to review a particular area of anatomy. Dr. Rhoton's last words to his fellows were 'keep working'. We will certainly do our best to follow his advice and his example.

The Rhoton Collection can be found here: http://rhoton. ineurodb.org 